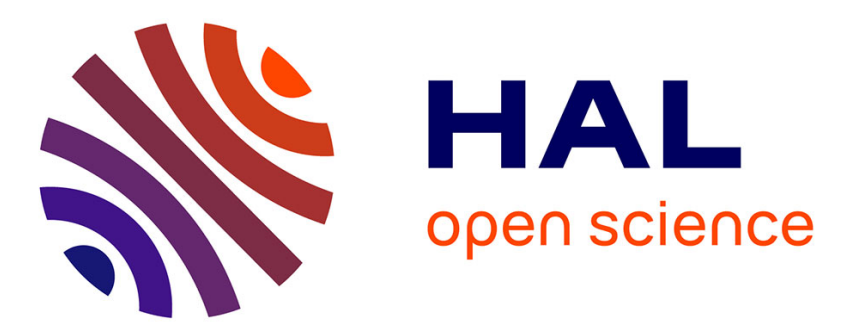

\title{
TiAl-based high temperature materials made from extremely deformed elemental powders
}

\author{
G.-X. Wang, M. Dahms, F. Pirwitz
}

\section{To cite this version:}

G.-X. Wang, M. Dahms, F. Pirwitz. TiAl-based high temperature materials made from extremely deformed elemental powders. Journal de Physique IV Proceedings, 1993, 03 (C7), pp.C7-469-C7-472. 10.1051/jp4:1993775 . jpa-00252195

\section{HAL Id: jpa-00252195 https://hal.science/jpa-00252195}

Submitted on 1 Jan 1993

HAL is a multi-disciplinary open access archive for the deposit and dissemination of scientific research documents, whether they are published or not. The documents may come from teaching and research institutions in France or abroad, or from public or private research centers.
L'archive ouverte pluridisciplinaire HAL, est destinée au dépôt et à la diffusion de documents scientifiques de niveau recherche, publiés ou non, émanant des établissements d'enseignement et de recherche français ou étrangers, des laboratoires publics ou privés. 


\title{
TiAl-based high temperature materials made from extremely deformed elemental powders
}

\author{
G.-X. WANG, M. DAHMS and F. PIRWITZ
}

Institute for Materials Research, GKSS Research Centre, Max-Planck-Str., 21502 Geesthacht, Germany

\begin{abstract}
Materials based on the intermetallic compound TiAl have been made from elemental powders which were extremely deformed through repeated coldextrusion or through combination of cold-extrusion and cold-rolling. The microstructure is getting finer with increasing deformation. After HIP at $1350^{\circ} \mathrm{C}$ under a pressure of $200 \mathrm{MPa}$ for 4 hours without encapsulation, the repeatedly extruded material showed a porosity of about $2 \%$, smaller than the porosity of simply extruded material ( $>6 \%$ ). Two-step sintering experiments carried out on the repeatedly extruded material showed that pores formed during pressureless sintering can be almost fully suppressed by an additional HIP treatment. On the contrary, the relatively low porosity HIP'ed material becomes more porous after a post pressureless sintering. In addition, TiAl matrix composites have been successfully prepared by pressing multilayerd rolied sheets, sandwiched with $\mathrm{Al}_{2} \mathrm{O}_{3}$ fibres or Mo foils, at high temperatures.
\end{abstract}

\section{Introduction}

Titanium aluminides as potential materials for high temperature applications are mostly produced using ingot metallurgy. However, the poor workability of titanium aluminides directs the attention to the production route of reactive powder metallurgy. This route includes following essential steps: mixing of elemental powders with desired composition, precompaction, cold-extrusion, and reactive sintering. During the reactive sintering, an external pressure is normally applied in order to suppress pore formation caused by different diffusivities of Ti- and Al-atome. This can be realized e.g. by hot isostatical pressing (HIP) asextruded materials. With this process, the poor workability of titanium aluminides is avoidad and nearly fully dence materials can be prepared by applying encapsulating techniques. Since encapsulation is normally very expensive, HIP without encapsulation is desirable in view of economy. Earlier work [1] showed that a large deformation of powders prior to HIPing is beneficial not only to increasing materials density but also to accelarating formation of titanium aluminides. A largely refined microstructure of the as-extruded material leads also to a reduction of pore size as well as porosity during reactive sintering [1]. The open porosity must be also reduced, so that the expensive encapsulation may be omitted. It was therefore attempted in this study to carry out HIP treatment of the extruded materials without encapsulaticn. Two-step sintering experiments were also conducted to see whether the more expensive HIP time can be shortend. In addition, TiAl matrix composites were successfully prepared by HIPing or HPing (hot pressing) multilayerd as-rolled sheets, sandwiched with $\mathrm{Al}_{2} \mathrm{O}_{3}$ fibres or Mo foils. 


\section{Experimental procedure}

Elemental powders with a size $<150 \mu \mathrm{m}$ were mixed in air using a tumbling mixer. The composition was Ti-34wt.\%Al, i.e., Ti-48at.\%Al. The powders used were water-atomized $99.5 \%$ pure aluminium and titanium sponge with the same purity. Green compacts were prepared at room temperature in an uniaxial pressing machine. Compacted billets were extruded at room temperature to bars with either a round cross-section of $12 \mathrm{~mm}$ diameter (extrusion ratio $\approx 17$ ) or a $10 \mathrm{~mm} \times 20 \mathrm{~mm}$ rectangular one (extrusion ratio $\approx 10$ ). Afterwards, the round bars were further extruded to give a total extrusion ratio of 350 , and those with a rectangular cross-section were cold-rolled to $0.5 \mathrm{~mm}$ and $0.1 \mathrm{~mm}$ thick sheets, with the rolling direction being perpendicular to the extrusion direction.

Both the simply (with extrusion ratio of 17) and repeatedly (with extrusion ratio of 350 ) extruded materials were hot isostatically pressed at $1350^{\circ} \mathrm{C}$ under a pressure of $200 \mathrm{MPa}$ for 4 hours without encapsulation. Since the cost for HIP treatment increases with increasing HIP time, it is of practical importance to reduce the HIP time. However, this is limited because of the time required to complete the reaction between elemental $\mathrm{Ti}$ and $\mathrm{Al}$ to form the intermetallics TiAl and $\mathrm{Ti}_{3} \mathrm{Al}$. In addition, the process of pore shrinkage during HIP is also time-dependent (creep process). In this respect, a two-step sintering, i. e. a combination of the relatively cheaper pressureless sintering and the expensive HIP treatment, seems to be reasonable. Therefore, two variations were carried out on the repeatedly extruded material:

Scheme 1: pressureless sintering $\left(1350^{\circ} \mathrm{C} / 6 \mathrm{~h}\right)+\mathrm{HIP}\left(1350^{\circ} \mathrm{C} / 4 \mathrm{~h} / 200 \mathrm{MPa}\right)$

Scheme 2: HIP $\left(1350^{\circ} \mathrm{C} / 4 \mathrm{~h} / 200 \mathrm{MPa}\right)+$ pressureless sintering $\left(1350^{\circ} \mathrm{C} / 6 \mathrm{~h}\right)$

In order to prepare TiAl matrix composites with strength and ductile reinforcements, HIPing and HPing of multilayered as-rolled sheets, sandwiched with $\mathrm{Al}_{2} \mathrm{O}_{3}$ fibres (as strength reinforcements) and Mo foils (as ductile reinforcements), respectively, were conducted. The following conditions were applied:

HIP: $\quad 1350^{\circ} \mathrm{C} / 2 \mathrm{~h} / 200 \mathrm{MPa}$

$\mathrm{HP}: \quad 1250^{\circ} \mathrm{C} / 2 \mathrm{~h} / 20 \mathrm{MPa}$

\section{Results}

\subsection{Microstructure of the as-extruded and as-rolled materials}

Figure 1 shows the as-extruded microstructures of extrusion ratios of 17 and 350 as well as the as-rolled microstructures of $0.5 \mathrm{~mm}$ and $0.1 \mathrm{~mm}$ thick sheets. It can be seen that the microstructure with extrusion ratio of 350 is much finer than that with extrusion ratio of 17 . Also the as-rolled microstructure is getting finer with reducing sheet thickness. Both $\mathrm{Ti}$ and $\mathrm{Al}$ powders are elongated in the extrusion or rolling direction to fibres. Almost no pores can be detected. The as-extruded as well as the as-rolled materials are strongly textured because of the alignment of both $\mathrm{Al}$ - and $\mathrm{Ti}$-fibres in extrusion direction. The reaction of elemental $\mathrm{Ti}$ and Al to intermetallics did not take place during extrusion, since only intensity peaks of pure Ti and Al were measured by $x$-ray difraction analysis [2]. These materials can be therefore easily machined or reformed to different shapes. This is of practical importance, since the presence of titanium aluminides would make the manufacture much more difficult.

\subsection{Porosity after HIP-treatment and two-step sinterings}

After HIPing at $1350^{\circ} \mathrm{C}$ under a pressure of $200 \mathrm{MPa}$ for 4 hours without encapsulation, a porosity of about $2.1 \%$ was measured on the repeatedly extruded material, lower than the porosity ( $>6 \%$ ) of the simply extruded material (Fig. 2).

The microstructures after both two-step sinterings are shown in Figs. $3 a$ and $3 b$, respectively. It 
is visible that the treatment scheme does influence the final porosity. The porosity after treatment of the scheme 1 is only $0.7 \%$, much smaller that that for the scheme $2(5.0 \%)$. The pores formed during pressureless sintering $1350^{\circ} \mathrm{C} / 6 \mathrm{~h}$ (about $2 \%$ [1]) have been almost fully suppressed by the additional HIP treatment (Fig. 3a). On the contrary, the relatively low density HIP'ed material (Fig. 2a) became more porous after the post pressureless sintering at 1350 0 $\mathrm{C} / 6 \mathrm{~h}$ (Fig. 3b).
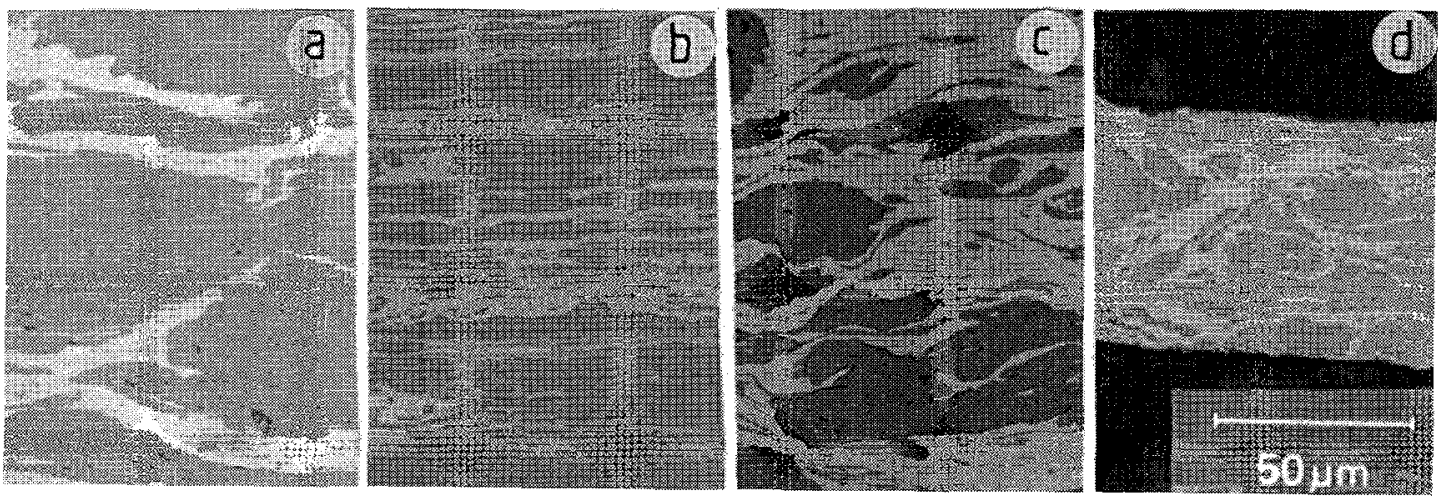

Fig. 1: As-extruded microstructures of extrusion ratios of 17 (a) and 350 (b) as well as the asrolled microstructures of $0.5 \mathrm{~mm}(c)$ and $0.1 \mathrm{~mm}(d)$ thick sheets
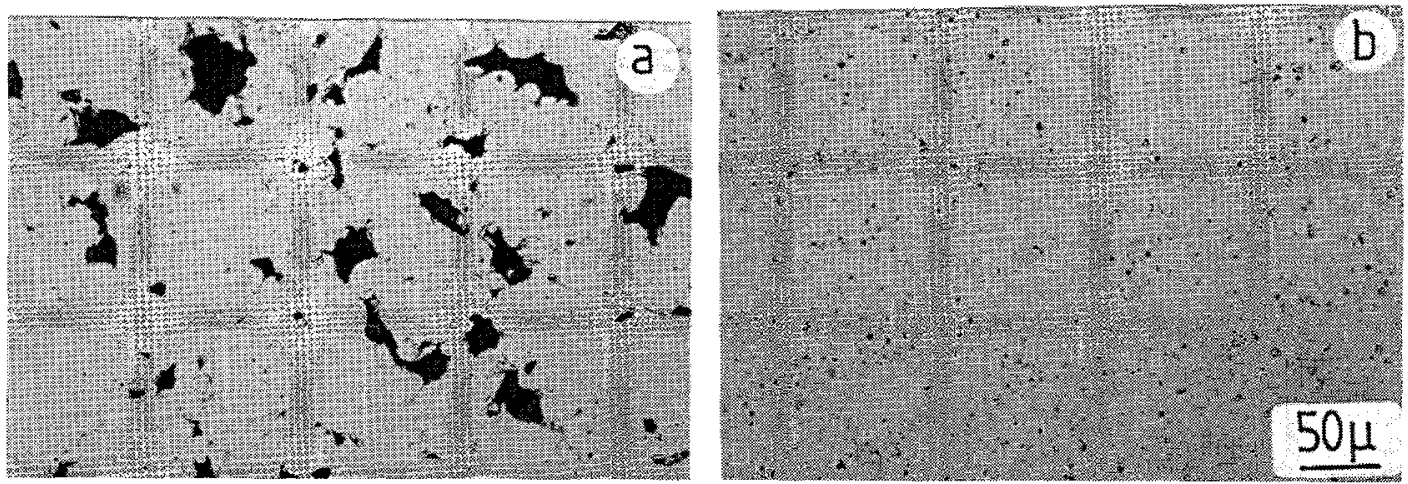

Fig. 2: Pores formed during HIP $\left(1350^{\circ} \mathrm{C} / 4 \mathrm{~h} / 200 \mathrm{MPa}\right)$ in specimens extruded with extrusion ratios of 17 (a) and $350(\mathrm{~b})$, respectively
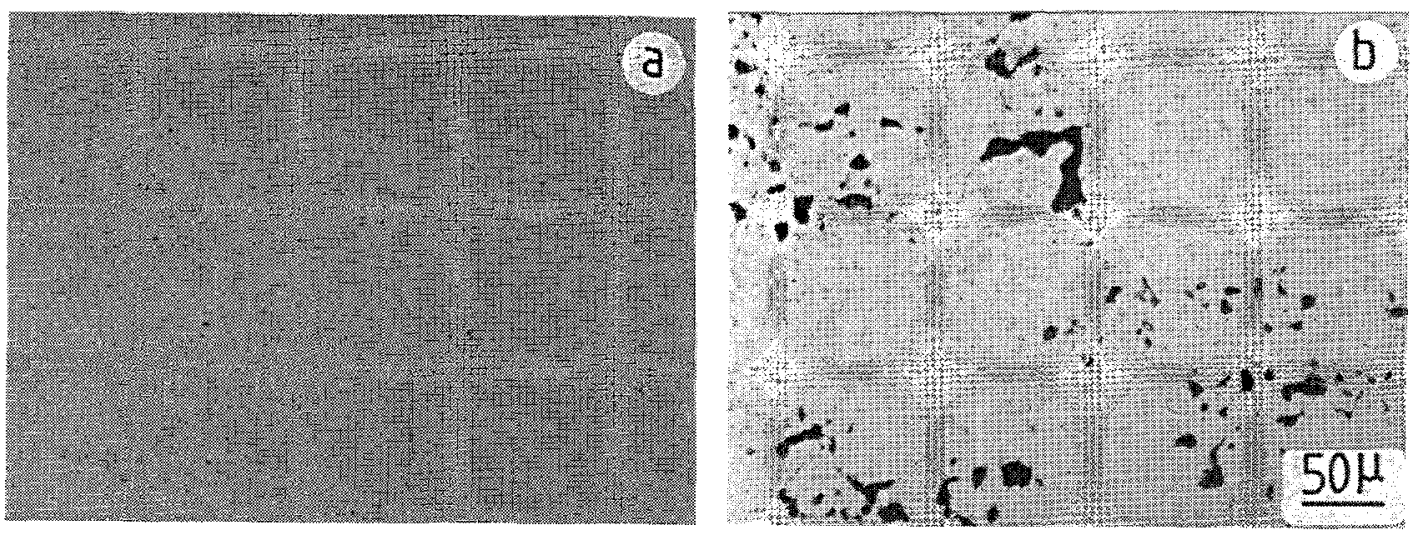

Fig. 3: Pores after two-step sinterings; (a) scheme 1 and (b) scheme 2 


\subsection{Microstructure of the composites}

Figure 4 shows the photographs taken from the prepared composites with $\mathrm{Al}_{2} \mathrm{O}_{3}$ fibres (Fig. 4a) and Mo foils (Fig. 4b). For TiAl+Al $\mathrm{O}_{3}$ composite (Fig. 4a), $0.1 \mathrm{~mm}$ thick sheets (Fig. 1d) were used, whereas use of $0.5 \mathrm{~mm}$ thick sheets (Fig. 1c) and $0.1 \mathrm{~mm}$ thick Mo foils was made for $\mathrm{TiAl}+\mathrm{Mo}$ composite (Fig. 4b). A duplex microstructure with lamellar $\mathrm{TiAl} / \mathrm{Ti}_{3} \mathrm{Al}$ grains in equiaxed TiAl-phase is seen in the TiAl matrices of both composites, with the lamellar volume fraction in $\mathrm{TiAl}+\mathrm{Al}_{2} \mathrm{O}_{3}$ composite being higher than in TiAl+Mo composite [3]. Part of the $\mathrm{Al}_{2} \mathrm{O}_{3}$ fibres in Fig. 4a were dissolved due to the high temperature of $1350^{\circ} \mathrm{C}$. The reaction zone between" TiAl and Mo exhibits a thickness of about 10-20 $\mu \mathrm{m}$ (Fig. 4b).

\section{Conclusions}

The results shown above can be summarized as below:

a. With increasing deformation, microstructure of consolidated elemental $\mathrm{Ti}$ and $\mathrm{Al}$ powder mixture becomes finer. This exerts a strong influence on the porosity formed during reaction HIP process without encapsulation. The finer the microstructure, the lower the porosity.

b. To reduce the more expensive HIP time, a combination of pressureless sintering and HIP can be done. The treatment sequence does affect the final porosity. For the repeatedly extruded material in this study, additional HIP after pressureless sintering leads to a porosity reduction. On the contray, an increase of porosity is observed after post pressureless sintering of the HIP'ed material, probably due to Ostwald ripening [2].

c. TiAl+ $\mathrm{Al}_{2} \mathrm{O}_{3}$ and TiAl+Mo composites can be prepared by HIPing or HPing multilayered asrolled sheets, sandwiched with $\mathrm{Al}_{2} \mathrm{O}_{3}$ fibres (as strength reinforcements) and Mo foils. (as ductile reinforcements), respectively. To limit the undesired reactions between TiAl matrix and the reinforcements, low temperatures should be applied for HIP or HP. But, the time required to complete the TiAl formation will be longer with decreasing temperature. An appropriate temperature range is still to be found out through more experiments in the futher.
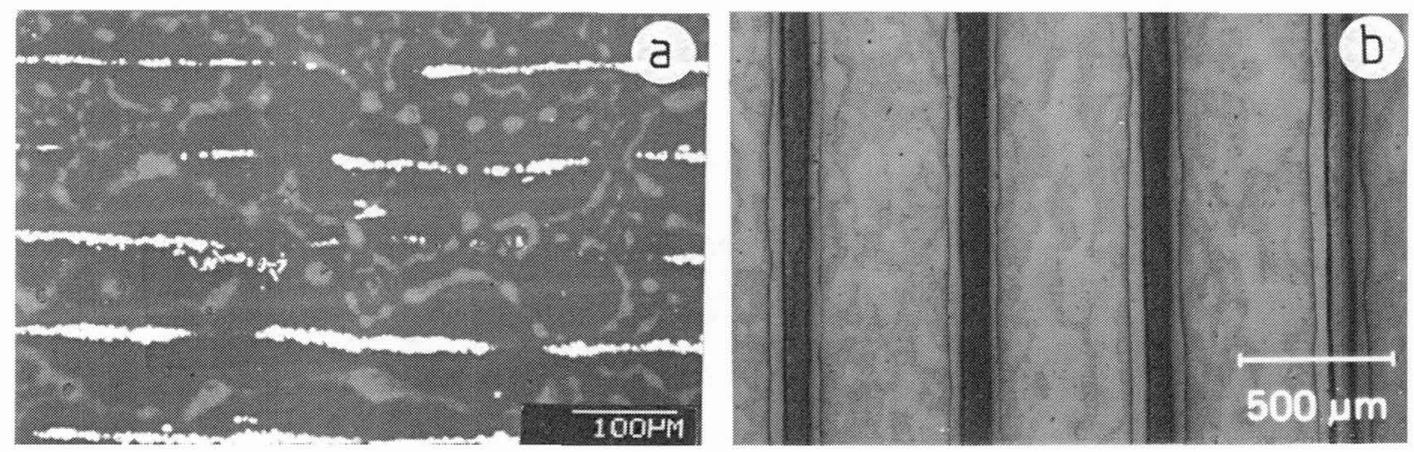

Fig. 4: Prepared composites; (a) $\mathrm{TiAl}+\mathrm{Al}_{2} \mathrm{O}_{3}$ and (b) $\mathrm{TiAl}+\mathrm{Mo}$

\section{Literature}

[1] G.-X. Wang, M. Dahms: "An Effective Method for Reducing Porosity in the Titanium Aluminide Alloy $\mathrm{Ti}_{52} \mathrm{Al}_{48}$ Prepared by Elemental Powder Metallurgy"Scripta Met. et Mat. Vol. 26 (1992), 1469-1474

[2] G.-X. Wang, M. Dahms: "Reaction Sintering of Cold Extruded Elemental Powder Mixture $\mathrm{Ti}_{52} \mathrm{Al}_{48}$ ", accepted for publication in Metall. Trans. A (1993)

[3] F. Pirwitz, M. Dahms, G.-X. Wang, S. W. Hülsmann, D. Nerger: "HIP-Synthesis of GammaBase Titanium-Aluminide Composites", to be published in proceedings of "HIP 93", Antwerp, Belgium, 21-23, April 1993 